\title{
Induction of human aortic myofibroblast-mediated extracellular matrix dysregulation: A potential mechanism of fluoroquinolone-associated aortopathy
}

\author{
David G. Guzzardi, PhD, Guoqi Teng, PhD, Sean Kang, BSc, BKin, Patrick J. Geeraert, \\ Simranjit S. Pattar, MBT, Daniyil A. Svystonyuk, PhD, Darrell D. Belke, PhD, and \\ Paul W. M. Fedak, MD, PhD
}

\section{ABSTRACT}

Objectives: Fluoroquinolone (FQ) antibiotics are associated with adverse aortic clinical events. We assessed human aortic myofibroblast-mediated extracellular matrix (ECM) dysregulation as a possible cellular mechanism underlying FQassociated aortopathy.

Methods: Human aortic myofibroblasts were isolated from patients with aortopathy undergoing elective ascending aortic resection $(\mathrm{N}=9)$. The capacity for extracellular matrix degradation in cells exposed to FQ was assessed by multiplex analysis of secreted matrix metalloproteinases relative to tissue inhibitors of matrix metalloproteinases (TIMPs). Direct evaluation of extracellular matrix degradation was investigated in human aortic cells using a 3-dimensional gelatin-fluorescein isothiocyanate fluorescence microgel assay. Aortic cellular collagen-1 expression following FQ exposure was determined by immunoblotting and immunofluorescent staining. Cell apoptosis, necrosis, and metabolic viability was determined by annexin-V, propidium iodide staining, and water-soluble tetrazolium salt (WST1) assay.

Results: FQ exposure significantly decreased aortic cell TIMP-1 $(P=.004)$ and TIMP-2 $(P=.0004)$ protein expression compared with vehicle control. The ratio of matrix metalloproteinase-9/TIMP-2 was increased suggesting an increased capacity for extracellular matrix degradation $(P=.01)$. In collagen gels, we show a trend toward increased aortic myofibroblast-mediated collagen fiber degradation with FQ exposure $(P=.09)$. Similarly, FQ exposure attenuated collagen-1 expression as assessed by immunoblotting $(P=.002)$ and immunofluorescence $(P=.02)$. Cell apoptosis, necrosis, and metabolic viability was not significantly influenced by FQ exposure.

Conclusions: For the first time, we document a putative mechanism underlying FQ-associated aortopathy whereby decreased TIMP expression with impaired compensatory collagen-1 expression results in human aortic myofibroblastmediated extracellular matrix dysregulation. These novel data may provide a cellular and molecular mechanism to explain the established clinical association between FQ exposure and acute aortic events. (J Thorac Cardiovasc Surg 2019;157:109-19)

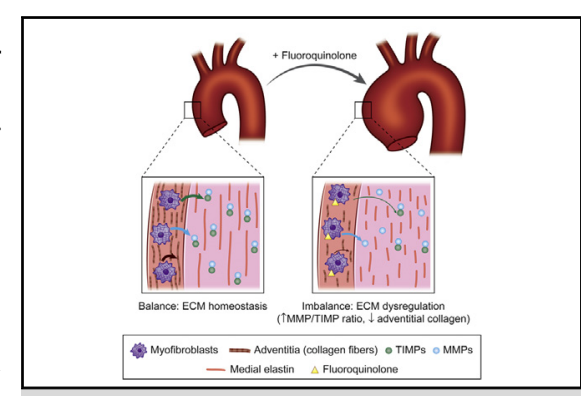

Fluoroquinolone induces aortic myofibroblastmediated extracellular matrix dysregulation.

\section{Central Message}

Fluoroquinolone antibiotics induce human aortic myofibroblast-mediated extracellular matrix dysregulation characterized by increased collagen degradation and impaired collagen deposition.

\section{Perspective}

Fluoroquinolone exposure in aortic myofibroblasts from patients with aortopathy can induce ECM dysregulation with increased degradation and impaired compensatory collagen production. These novel data provide a possible cellular mechanism underlying the wellestablished clinical association between fluoroquinolone drug exposure with increased risk of aortic aneurysm and acute aortic events.

See Editorial Commentaries pages 120 and 122.

\footnotetext{
From the Section of Cardiac Surgery, Department of Cardiac Sciences, Libin Cardiovascular Institute of Alberta, Cumming School of Medicine, University of Calgary, Calgary, Alberta, Canada.

Supported by an Alberta Innovates-Health Solutions (AIHS) MD-PhD studentship (Dr Guzzardi and Dr Svystonyuk), an AIHS MSc Studentship (Mr Kang) and an AIHS Summer Studentship (Mr Geeraert).

Read at The American Association for Thoracic Surgery Aortic Symposium 2018, New York, New York, April 26-27, 2018.
}

Received for publication April 17, 2018; revisions received Aug 20, 2018; accepted for publication Aug 23, 2018; available ahead of print Oct 25, 2018. Address for reprints: Paul W. M. Fedak, MD, PhD, Room 880, 1403-29 St, NW, Calgary, Alberta, Canada T2N 2T9 (E-mail: paul.fedak@gmail.com). $0022-5223 / \$ 36.00$

Copyright (C) 2018 by The American Association for Thoracic Surgery https://doi.org/10.1016/j.jtcvs.2018.08.079 


\section{Abbreviations and Acronyms \\ $3 \mathrm{D}=3$ dimensional \\ $\mathrm{CTCF}=$ corrected total cell fluorescence \\ $\mathrm{ECM}=$ extracellular matrix \\ FITC = fluorescein isothiocyanate \\ FQ $\quad$ fluoroquinolones \\ MMP $=$ matrix metalloproteinase \\ PBS $=$ phosphate buffered saline \\ SFM $=$ serum-free media \\ SDS-PAGE $=$ sodium dodecyl sulfate polyacrylamide gel electrophoresis \\ TIMP $=$ tissue inhibitor of matrix metalloproteinase \\ WST1 = water-soluble tetrazolium salt}

Aortopathy is a life-threatening disease complicated by its frequently indolent nature. ${ }^{1}$ Collectively, aortopathy is the maladaptive remodeling of the aortic wall resulting in progressive weakening, aneurysmal dilatation, dissection, or catastrophic rupture. ${ }^{2}$ Although the link between inherent extracellular matrix (ECM) defects and aortic disease is well established, an understanding of acquired mechanisms of aortopathy has proved elusive, particularly in patients with pre-existent aortic pathology. Emerging evidence supports pharmacologic-associated aortopathy in patients receiving fluoroquinolone (FQ) antibiotics. ${ }^{3-6}$ Compared with patients receiving amoxicillin antibiotics, those receiving FQ have a $66 \%$ higher risk of aneurysm or dissection within a 2-month period after commencing FQ use. $^{6}$ Coupled with more than 27 million annual FQ prescriptions in the United States alone, ${ }^{7}$ FQ-associated aortopathy constitutes a considerable clinical problem. Although a strong association is observed between FQ exposure and development of aortopathy with acute events, ${ }^{5,6}$ a causal cellular or molecular mechanism is lacking, resulting in continued widespread FQ use in patients at risk of aortic complications. ${ }^{7}$ Previous studies investigating the influence of FQ on adult mammalian cells are limited to tendon and cartilage where its exposure is linked with tenocyte ECM degradation by altered matrix metalloproteinase (MMP) and tissue inhibitors of MMP (TIMP) levels, as well as collagen production. ${ }^{8-12}$ No such studies exist in the cardiovascular system, and it is unclear whether similar mechanisms may coordinate aortic ECM degeneration given its unique biological, rheological, and mechanical environment. Myofibroblasts comprise an abundant cell population within the aortic wall adventitia with a capacity for structural arterial ECM remodeling. ${ }^{13-19}$ We hypothesized that human aortic myofibroblasts from aortopathy patients may increase their capacity for maladaptive ECM remodeling following exposure to FQ.

\section{MATERIALS AND METHODS \\ Human Aortic Myofibroblast Isolation and Characterization}

With institutional review board approval, aortic myofibroblasts were isolated and expanded from the adventitial aortic tissue of consenting patients $(\mathrm{N}=9)$ undergoing elective ascending aortic surgery using previously described methods of cell explantation. ${ }^{20}$ For comparison, 2 patients undergoing nonaortic cardiac surgery provided atrial cardiac myofibroblasts as before. ${ }^{20}$ Cells were grown on $0.1 \%$ gelatin-coated 100-mm Petri dishes (Falcon, Corning, NY) with Iscove's modified Dulbecco's medium (Lonza, Walkersville, Md) supplemented with 50,000 U penicillin-streptomycin (Life Technologies, Burlington, Ontario, Canada) and 10\% fetal bovine serum (complete media; Life Technologies). Explants were cultured at $37^{\circ} \mathrm{C}$ in $5 \%$ carbon dioxide with media changes every 4 days for a maximum of 4 weeks before use in experiments. Cell harvests involved phosphate-buffered saline (PBS) (Lonza) washing and enzymatic treatment with $0.25 \%$ trypsin-ethylenediaminetetraacetic acid (Gibco, Life Technologies) for 3 minutes at $37^{\circ} \mathrm{C}$. Unless noted, all experiments involved growing cells on $0.1 \%$ gelatin-coated plates or coverslips for 24 hours in complete media, followed by 24 hours of serumfree media (SFM) (complete media without 10\% fetal bovine serum). Cells were then incubated in treatment solutions for 48 hours before collection or running the relevant assay. Confirmation of aortic myofibroblast phenotype was conducted by morphologic inspection and immunofluorescent staining as before. ${ }^{20}$ Briefly, cells were grown on sterile coverslips, fixed with 4\% paraformaldehyde (Electron Microscopy Sciences, Hatfield, $\mathrm{Pa}$ ) and permeabilized in blocking buffer containing $2 \%$ goat serum (Jackson ImmunoResearch Laboratories, West Grove, $\mathrm{Pa}$ ), $1 \%$ bovine serum (Sigma-Aldrich, St Louis, Mo) and $0.1 \%$ Triton X-100 (EMD Millipore, Toronto, Ontario, Canada). Cells were incubated with primary antibodies at a 1:300 dilution: mouse antifibronectin (Calbiochem; EMD Millipore), mouse antifibroblast surface protein (Sigma-Aldrich), mouse antismoothelin (Abcam, Toronto, Ontario, Canada), rabbit anti-von Willibrand factor, rabbit antivimentin, or rabbit antidesmin (all from Santa Cruz Biotechnology, Dallas, Tex). Alexa Fluor 555 goat antimouse or Alex Fluor 488 goat antirabbit secondary antibodies (Life Technologies) were used at a 1:500 dilution. Cells were stained with bisBenzimide H 33342 trihydrochloride (Hoechst stain; Sigma-Aldrich) for nuclear visualization and mounted onto glass microscope slides using Prolong Gold Antifade Reagent (Life Technologies). Immunofluorescent images were captured using confocal laser microscopy (LSM 5; Carl Zeiss, Toronto, Ontario, Canada).

\section{Reagent Preparation}

Ciprofloxacin (Sigma-Aldrich) dissolved in hydrochloric acid was diluted in SFM to obtain 100, 250, and $500 \mu \mathrm{M}$ tissue-relevant concentrations of FQ used before, ${ }^{21}$ and reflective of approximate ciprofloxacin concentrations to which the kidney is exposed. ${ }^{22}$ Hydrochloric acid diluted in 
SFM $(0.08 \mu \mathrm{M}$; the same hydrochloric acid concentration in $500 \mu \mathrm{M} \mathrm{FQ})$ served as $0 \mu \mathrm{M}$ vehicle control, whereas SFM alone served as the negative (untreated) control.

\section{Multiplex Protein Quantification}

Cells $(50,000 / w e l l)$ were grown in triplicate on 24-well plates (Falcon). Conditioned media was collected and analyzed for MMP and TIMP concentrations by multiplex fluorescent bead assay (Eve Technologies, Calgary, Alberta, Canada).

\section{Assessment of Myofibroblast-Mediated Gelatin Degradation}

We assessed morphologic changes in individual aortic myofibroblasts and their ability to degrade ECM using a modified three-dimensional (3D) collagen matrix platform as described before. ${ }^{20}$ Briefly, serumstarved cells were seeded in treatment solution at low density (5000/grid) onto 3D type I bovine collagen (Advanced Biomatrix, San Diego, Calif) polymerized in rigid (noncontractile) nylon grids with $1 \%$ fluorescein isothiocyanate (FITC)-conjugated gelatin. Gelatin-FITC fluoresces when degraded by cellular gelatinases and serves as a functional measure of overall protease activity. Treatments $(0,100,250$, and $500 \mu \mathrm{M}$ FQ) were supplemented with $10 \mathrm{ng} / \mathrm{mL}$ transforming growth factor $\beta-1$ (Gibco, Life Technologies) and maintained for 24 hours. Confocal laser microscopy was used to visualize cell morphology and nuclear staining using Alex Fluor 555 phalloidin (Life Technologies) and Hoechst stain, respectively. Blinded analysis of gelatin-FITC fluorescence by cells relative to their surrounding 3D collagen matrix was evaluated in the 3D plane where the nucleus was most visible according to the formula for corrected total cell fluorescence $(\mathrm{CTCF}):^{23}$

$$
\begin{array}{r}
C T C F=\text { integrated density }-(\text { area of selected cell } \\
\times \text { mean fluorescence of background reading })
\end{array}
$$

\section{Immunoblotting}

Cells (250,000/well) were grown on 6-well plates (VWR, Radnor, Pa) and the cell lysate collected in radioimmunoprecipitation assay buffer (Millipore, Temecula, La). Samples were run on a 6\% sodium dodecyl sulfate polyacrylamide gel electrophoresis gel and transferred onto a nitrocellulose membrane (Millipore). Membranes were blocked in 5\% skim milk in Tris-buffered saline $+0.05 \%$ Tween (EMD Millipore) and probed at a 1:2000 dilution of primary antibodies for collagen-1 (Abcam) and glyceraldehyde 3-phosphate dehydrogenase (Santa Cruz Biotechnology). Antimouse (Cedarlane, Burlington, Ontario, Canada) or anti-rabbit (SigmaAldrich) horseradish peroxide-conjugated secondary antibodies at a dilution of 1:2000, and ECL Western Blotting Substrate (Thermo-Fisher Scientific, Rockford, Ill) were used to resolve blots. Images were captured using a gel imaging system (ImageQuant LAS 4000; General Electric, Toronto, Ontario, Canada) and collagen-1 optical density was quantified relative to GAPDH loading controls using ImageJ (National Institutes of Health, Bethesda, Md).

\section{Immunofluorescent Staining}

Cells (50,000/coverslip) were grown on sterile coverslips. As above, cells were fixed in $4 \%$ paraformaldehyde for 20 minutes at $23^{\circ} \mathrm{C}$ followed by PBS washing, and permeabilized in blocking buffer containing $2 \%$ goat serum, $1 \%$ bovine serum, and $0.1 \%$ Triton X-100 (EMD Millipore). Coverslips were incubated in rabbit anti-collagen-1 antibody (1:300 dilution; Abcam, Cambridge, Mass) overnight at $4{ }^{\circ} \mathrm{C}$. Following PBS washing, cells were incubated in Alex Fluor 488 goat antirabbit secondary antibody (1:500 dilution) for 1 hour at $23^{\circ} \mathrm{C}$, washed with PBS, and stained with Hoechst for nuclear visualization. Coverslips were mounted onto glass microscope slides using Prolong Gold
TABLE 1. Patient demographic characteristics of ascending aortic

\begin{tabular}{|c|c|}
\hline Preoperative characteristics & Patients $(\mathbf{N}=\mathbf{9})$ \\
\hline Age (y) & $56 \pm 13$ \\
\hline Female & $1(11)$ \\
\hline $\begin{array}{l}\text { Aortic valve morphology } \\
\text { BAV } \\
\text { TAV }\end{array}$ & $\begin{array}{l}7(78) \\
2(22)\end{array}$ \\
\hline $\begin{array}{l}\text { Aortic valve function } \\
\text { AS: None/mild/moderate-severe } \\
\text { AR: None/mild/moderate-severe } \\
\text { Mixed AS and AR (all severities) }\end{array}$ & $\begin{array}{c}5(56) / 0(0) / 3(33) \\
3(33) / 0(0) / 5(56) \\
1(11)\end{array}$ \\
\hline $\begin{array}{l}\text { Ascending aorta diameter }(\mathrm{cm}) \\
\text { Sinus of Valsalva } \\
\text { Midascending aorta }\end{array}$ & $\begin{array}{l}4.6 \pm 0.6(3.6-5.4) \\
5.2 \pm 0.3(4.7-5.8)\end{array}$ \\
\hline $\begin{array}{l}\text { Cardiovascular risk factors } \\
\text { Hypertension } \\
\text { Dyslipidemia } \\
\text { Diabetes } \\
\text { Smoking history }\end{array}$ & $\begin{array}{l}5(56) \\
3(33) \\
0(0) \\
2(22)\end{array}$ \\
\hline Congestive heart failure & $2(22)$ \\
\hline $\begin{array}{l}\text { Surgical procedure: Aortic valve } \\
\text { Repair } \\
\text { Replacement } \\
\text { AVR: Tissue/mechanical } \\
\text { Bentall } \\
\text { Ross }\end{array}$ & $\begin{aligned} 2(22) \\
7(78) \\
4(44) / 3(33) \\
3(33) \\
0(0)\end{aligned}$ \\
\hline $\begin{array}{l}\text { Surgical procedure: Ascending aorta } \\
\text { Ascending aorta replacement } \\
\text { Root replacement } \\
\text { Hemiarch }\end{array}$ & $\begin{array}{l}8(89) \\
5(56) \\
0\end{array}$ \\
\hline Concomitant $\mathrm{CABG}$ & $2(22)$ \\
\hline
\end{tabular}
adventitial tissue biopsies

Values are presented as mean \pm standard deviation (range) or $\mathrm{n}(\%) . B A V$, Bicuspic aortic valve; $T A V$, tricuspid aortic valve; $A S$, aortic stenosis; $A R$, aortic regurgitation; $A V R$, aortic valve replacement; $C A B G$, coronary artery bypass grafting.

Antifade Reagent (Sigma-Aldrich), and 3 different immunofluorescent images captured from each coverslip using confocal laser microscopy. Analysis by blinded observation of cells in all 3 fields of view were conducted according to the CTCF formula.

\section{Cell Apoptosis and Necrosis}

Cells $(250,000 /$ well $)$ were grown on 6-well plates and collected in cold binding buffer. Cell suspensions were stained for annexin- $\mathrm{V}$ and propidium iodide according to the manufacturer's instructions (BD Pharmingen, Becton Dickinson, San Jose, Calif), and quantified using flow cytometry.

\section{Cell Metabolic Viability}

Cells $(10,000 / w e l l)$ were grown in triplicate on 96-well plates (ThermoFisher Scientific). Metabolic activity was measured using the colorimetric tetrazolium salt (WST1) assay (Roche Life Science, Indianapolis, Ind) according to the manufacturer's instructions. WST1 cleavage by mitochondrial dehydrogenases to formazan results in a color change indicative of cell viability. The absorbance at $450 \mathrm{~nm}$ was measured 60 minutes after WST1 solution addition to treatment wells using a BioTek Synergy Mx microplate reader (BioTek Instruments Inc, Winooski, Vt), and values were subtracted from background (wells without cells) as before. ${ }^{20}$ 

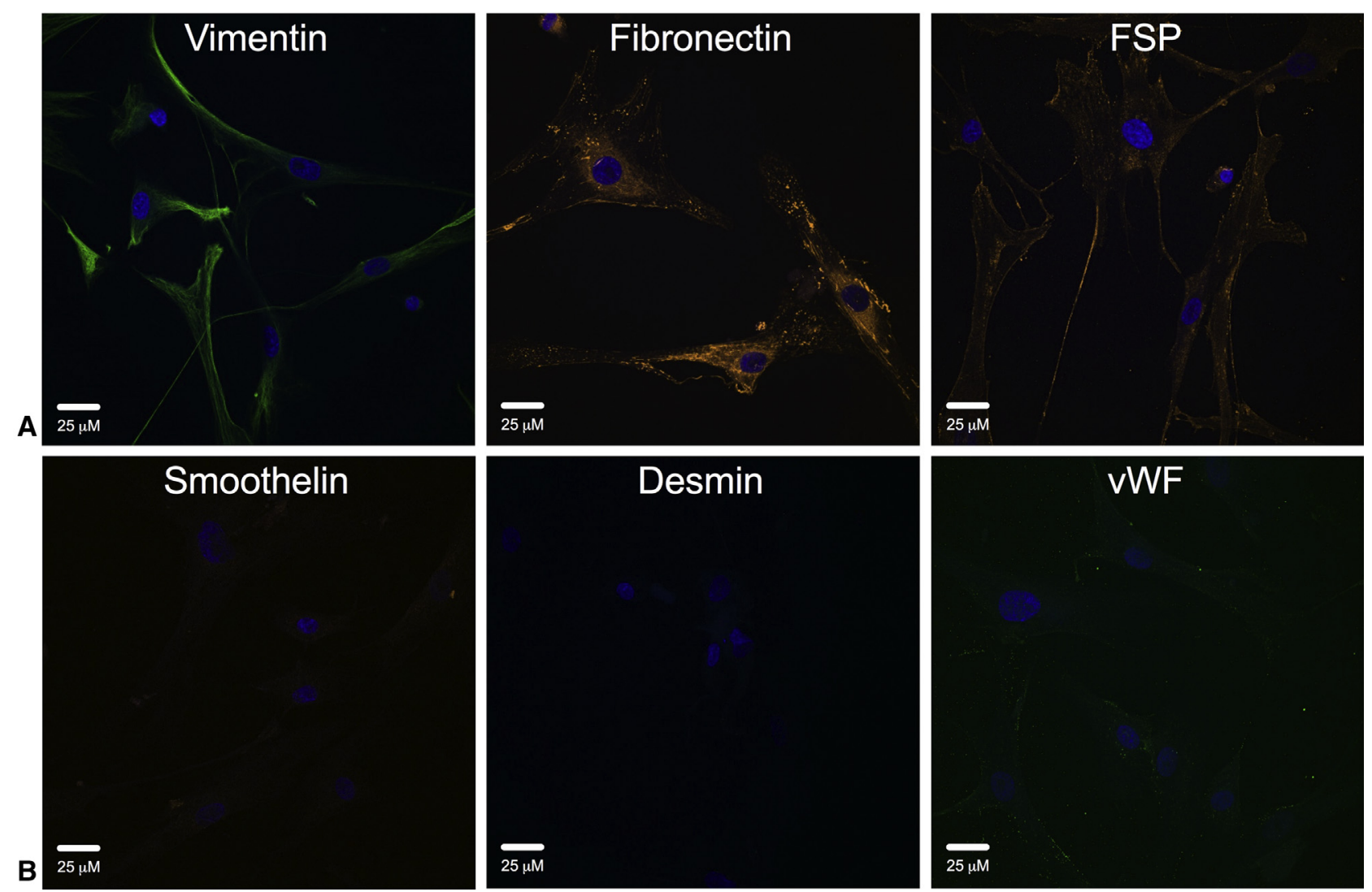

FIGURE 1. Characterization of human aortic adventitial myofibroblasts. A, Cells stained positive for markers of myofibroblasts: vimentin ( $g r e e n$ ), fibronectin (orange), and fibroblast surface protein (FSP) (orange). B, Cells stained negative for markers of nonmyofibroblast cells of the aortic wall: smoothelin (orange), desmin (green) (both indicative of smooth muscle cells), and von Willibrand factor ( $v W F$; endothelial cells) (green). Immunofluorescent staining of indicated protein is in orange or green; nuclear staining (Hoechst stain) is in blue. White line indicates scale.

\section{Statistical Analyses}

Normality was assessed using the Shapiro-Wilk test and nonnormally distributed data are reported as median (interquartile range [IQR]). FQ treatments were compared with vehicle control using Friedman's test alongside Dunn's test used for multiple comparisons. Data are shown relative to untreated cells. Statistical analyses were conducted using GraphPad Prism 6.0 (GraphPad Software, La Jolla, Calif).

\section{RESULTS}

\section{Patient Demographic Characteristics}

Patient characteristics $(\mathrm{N}=9)$ from whom aortic myofibroblasts were isolated and used for experiments are reported in Table 1. All patients received ascending aortic and/or aortic root surgery for aortopathy $(\mathrm{n}=8[89 \%]$ and $\mathrm{n}=5[56 \%]$, respectively). Most were male $(\mathrm{n}=8[89 \%])$ and had bicuspid aortic valves $(\mathrm{n}=7[78 \%])$, with an average midascending aortic diameter of $5.2 \pm 0.3 \mathrm{~cm}$. All patients had valve dysfunction and most $(\mathrm{n}=7$ [78\%]) underwent aortic valve replacement for either moderate-severe aortic stenosis $(\mathrm{n}=3[33 \%])$ or regurgitation $(\mathrm{n}=5[56 \%]) ; 2$ patients $(22 \%)$ underwent aortic valve repair with valve-sparing root replacement.

\section{Human Aortic Myofibroblast Characterization}

Cell morphology and immunofluorescent staining were used to characterize cell phenotype. Morphology was consistent with myofibroblasts (Figure 1). Cells (>95\%) also stained positive for vimentin, fibronectin, and fibroblast surface protein, representing specific myofibroblast cell markers (Figure 1, A). To ensure specificity of phenotype, cells were stained for nonmyofibroblast cell markers (Figure 1, B). All cells stained negative for smoothelin and desmin (smooth muscle cells) and von Willibrand factor (endothelial cells).

\section{FQ Induces Human Aortic Myofibroblast-Mediated ECM Dysregulation}

To determine the influence of FQ on cellular ECM regulation, MMP and TIMP protein release by human aortic myofibroblasts was assessed by multiplex protein analysis after FQ exposure. TIMP-1, -2, and -4 protein abundance was significantly decreased by $500 \mu \mathrm{M}$ FQ compared with vehicle (0 $\mu \mathrm{M}$ FQ) (Figure 2, $A$ and $B$, and Table 2). Decreased TIMP-2 abundance was also observed following $250 \mu \mathrm{M}$ FQ exposure. For comparison, atrial cardiac 

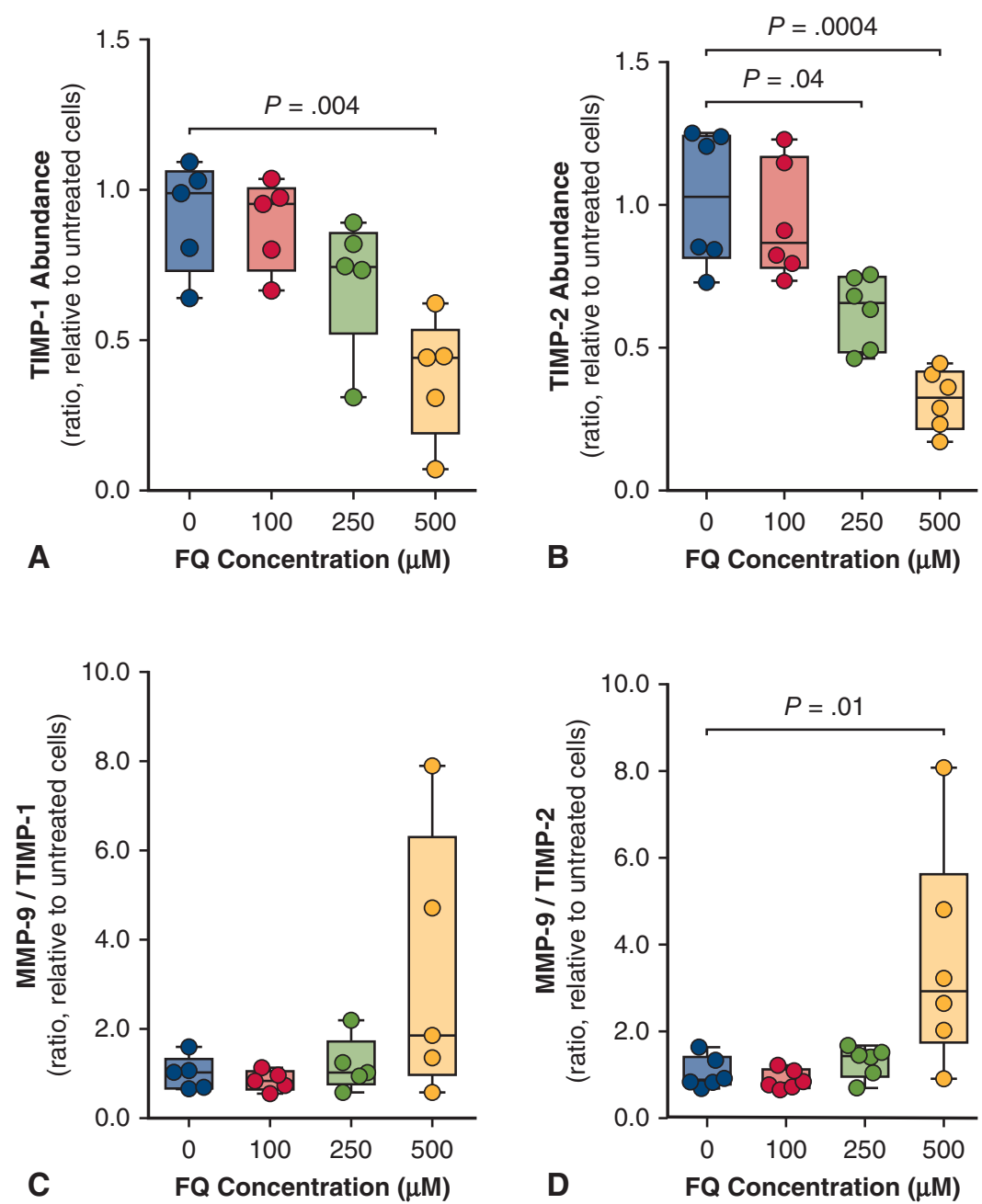

FIGURE 2. Abundances of matrix metalloproteinases (MMPs) and tissue inhibitors of MMPs (TIMPs) protein released by human aortic myofibroblasts exposed to fluoroquinolone $(F Q)$, relative to untreated cells. A and B, TIMP-1 and -2. C and D, Ratios of MMP-9 to TIMP-1 and TIMP-2 concentrations. Horizontal lines denote median values and $P$ values indicate comparison to $0 \mu \mathrm{M}$ FQ (Friedman's test with Dunn's test for multiple comparisons). There were 5 replicates for panels A and C and 6 replicates for panels B and D.

myofibroblast exposed to FQ showed similar decreases in TIMP-1 and TIMP-2 (Figure E1, $A$ and $B$ ). A modest decrease in MMP-1 abundance in response to $250 \mu \mathrm{M}$ $\mathrm{FQ}$, and MMP-2, -3 , and -10 abundance following exposure to 250 and $500 \mu \mathrm{M}$ FQ compared with vehicle was also observed (Table 2). In contrast, MMP-9 and -13 abundances were unchanged at all doses of FQ exposure. Given the critical role of MMP-9 as a mediator of aortopathy, ${ }^{24-26}$ and the 1:1 stoichiometric relationship whereby TIMPs act as endogenous inhibitors of MMPs,${ }^{27}$ we assessed the relative balance of specific MMP and TIMP expressions. As an index of ECM degrading capacity, MMP-9/TIMP-1 and MMP-9/TIMP-2 ratios were calculated. MMP-9/TIMP-1 ratio increased with exposure to FQ and MMP-9/TIMP-2 was significantly elevated with $\mathrm{FQ}$ exposure relative to $0 \mu \mathrm{M}$ FQ vehicle control (Figure 2, $C$ and $D$, and
Table 2). We next explored the direct effects of FQ exposure on cell-mediated ECM degradation using a novel model of 3D collagen-1 gelatin-FITC degradation to model a human aortic ECM microenvironment. In this microgel assay, gelatin-FITC fluorescence from individual human aortic myofibroblasts is observed in proportion to the extent of gelatinase-mediated ECM collagen-1 degradation. We observed increased fluorescence in response to $500 \mu \mathrm{M}$ FQ exposure relative to vehicle-treated cells (1.47 fluorescent units [IQR, 1.34-1.91 fluorescent units] vs 0.73 fluorescent units [IQR, 0.55-1.07 fluorescent units]; $P=.09$ ) (Figure 3, $A$ and $B$ ). Collectively, these data indicate that FQ alters the balance of MMP:TIMP expression in human aortic myofibroblasts toward increased MMP protease activity resulting in maladaptive cell-mediated collagen fiber degeneration. 
TABLE 2. Matrix metalloproteinase (MMP) and tissue inhibitor of MMP (TIMP) protein species released by human aortic myofibroblasts after fluoroquinolone (FQ) exposure

\begin{tabular}{|c|c|c|c|c|c|}
\hline Species & FQ concentration $(\mu \mathrm{M})$ & $\begin{array}{l}\text { Median abundance (ratio, } \\
\text { relative to untreated cells) }\end{array}$ & $\begin{array}{l}\text { IQR (ratio, relative to } \\
\text { untreated cells) }\end{array}$ & $\begin{array}{c}\text { Friedman's test } \\
P \text { value* }\end{array}$ & $\begin{array}{c}\text { Dunn's test } \\
P \text { value* }\end{array}$ \\
\hline \multirow[t]{4}{*}{ MMP-1 } & 0 & 0.96 & $0.77-1.19$ & .03 & - \\
\hline & 100 & 0.86 & $0.67-1.17$ & & .99 \\
\hline & 250 & 0.64 & $0.44-0.76$ & & .04 \\
\hline & 500 & 0.24 & $0.12-1.73$ & & .08 \\
\hline \multirow[t]{4}{*}{ MMP-2 } & 0 & 0.96 & $0.83-1.33$ & .0001 & - \\
\hline & 100 & 0.73 & $0.63-1.00$ & & .54 \\
\hline & 250 & 0.56 & $0.45-0.63$ & & .02 \\
\hline & 500 & 0.22 & $0.15-0.27$ & & .0002 \\
\hline \multirow[t]{4}{*}{ MMP-3 } & 0 & 1.08 & $0.96-1.34$ & .006 & - \\
\hline & 100 & 0.90 & $0.76-1.01$ & & .35 \\
\hline & 250 & 0.64 & $0.47-0.87$ & & .04 \\
\hline & 500 & 0.57 & $0.35-1.30$ & & .01 \\
\hline \multirow[t]{4}{*}{ MMP-9 } & 0 & 0.80 & $0.63-1.10$ & .51 & - \\
\hline & 100 & 0.76 & $0.54-0.92$ & & .99 \\
\hline & 250 & 0.72 & $0.55-0.84$ & & .79 \\
\hline & 500 & 0.70 & $0.49-0.93$ & & .54 \\
\hline \multirow[t]{4}{*}{ MMP-10 } & 0 & 1.08 & $0.94-1.22$ & .009 & - \\
\hline & 100 & 0.86 & $0.71-1.00$ & & .79 \\
\hline & 250 & 0.53 & $0.44-0.68$ & & .03 \\
\hline & 500 & 0.49 & $0.26-1.09$ & & .01 \\
\hline \multirow[t]{4}{*}{ MMP-13 } & 0 & 1.06 & $0.92-1.72$ & .36 & - \\
\hline & 100 & 1.04 & $0.87-1.17$ & & .99 \\
\hline & 250 & 0.94 & $0.85-1.17$ & & .79 \\
\hline & 500 & 0.95 & $0.80-1.12$ & & .44 \\
\hline \multirow[t]{4}{*}{ TIMP-1 } & 0 & 0.99 & $0.73-1.06$ & .0001 & - \\
\hline & 100 & 0.95 & $0.73-1.00$ & & .99 \\
\hline & 250 & 0.75 & $0.52-0.86$ & & .15 \\
\hline & 500 & 0.44 & $0.19-0.53$ & & .004 \\
\hline \multirow[t]{4}{*}{ TIMP-2 } & 0 & 1.03 & $0.81-1.24$ & .0001 & - \\
\hline & 100 & 0.87 & $0.78-1.17$ & & .99 \\
\hline & 250 & 0.66 & $0.48-0.75$ & & .04 \\
\hline & 500 & 0.32 & $0.22-0.42$ & & .0004 \\
\hline \multirow[t]{4}{*}{ TIMP-4 } & 0 & 0.90 & $0.79-1.16$ & .04 & - \\
\hline & 100 & 0.94 & $0.65-1.25$ & & .99 \\
\hline & 250 & 0.70 & $0.63-0.74$ & & .79 \\
\hline & 500 & 0.39 & $0.36-0.65$ & & .04 \\
\hline \multirow[t]{4}{*}{ MMP-9/TIMP-1 } & 0 & 1.03 & $0.68-1.33$ & .15 & - \\
\hline & 100 & 0.83 & $0.64-1.05$ & & .99 \\
\hline & 250 & 1.02 & $0.76-1.72$ & & .99 \\
\hline & 500 & 1.86 & $0.97-6.30$ & & .26 \\
\hline \multirow[t]{4}{*}{ MMP-9/TIMP-2 } & 0 & 0.88 & $0.79-1.41$ & .0006 & - \\
\hline & 100 & 0.81 & $0.70-1.13$ & & .99 \\
\hline & 250 & 1.43 & $0.96-1.56$ & & .79 \\
\hline & 500 & 2.93 & $1.75-5.62$ & & .01 \\
\hline
\end{tabular}

$I Q R$, Interquartile range. * $P$ values denote global Friedman's test and Dunn's test for multiple comparisons relative to $0 \mu \mathrm{M} F Q$ vehicle control, respectively. Boldface type indicates $P<.05$. 
A
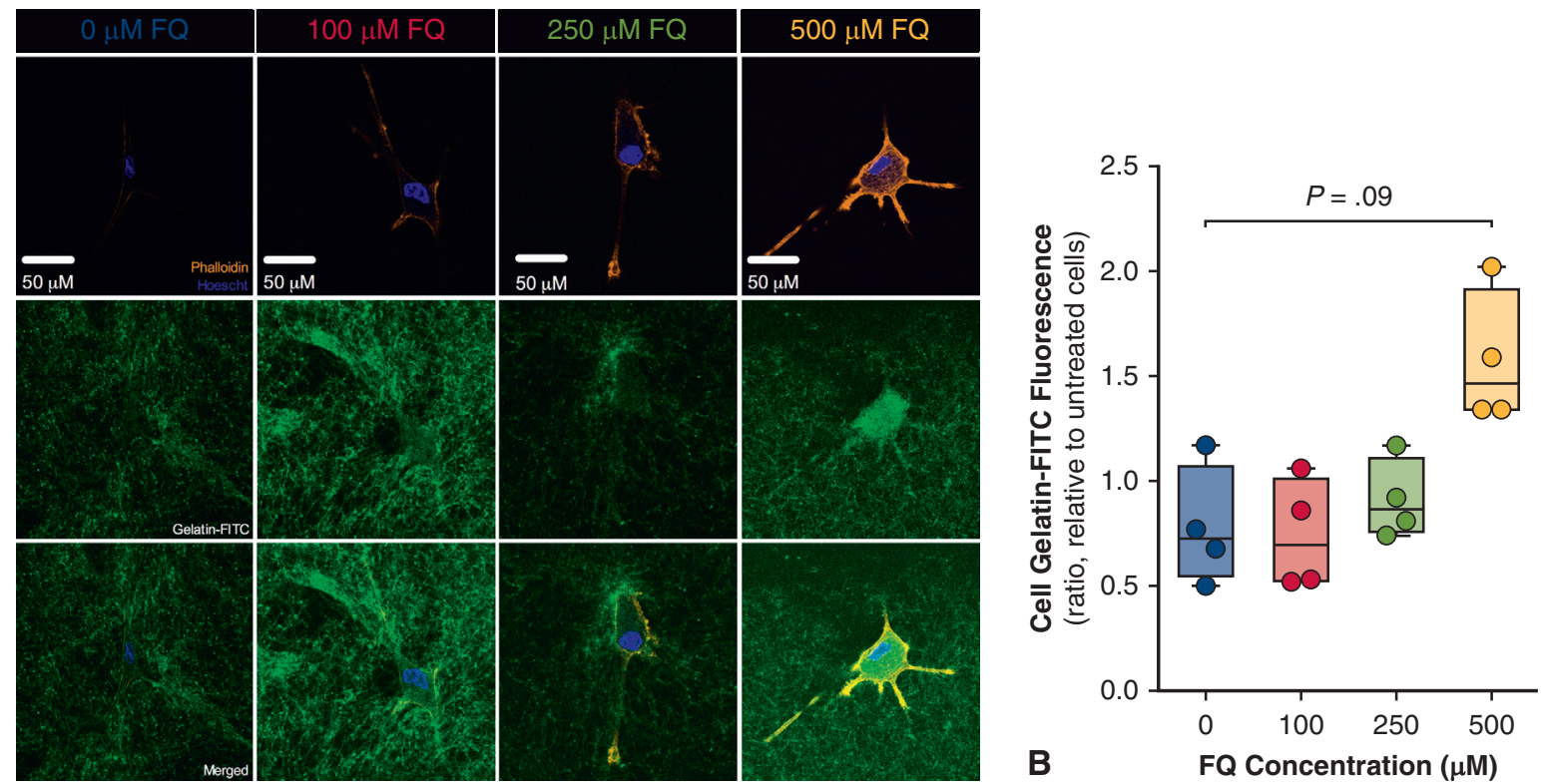

FIGURE 3. Assessment of human aortic myofibroblast-mediated gelatinase activity (compared to background) by 3-dimensional fluorescein isothiocyanate (FITC)-conjugated gelatin in response to fluoroquinolone exposure. A, Representative images of cell gelatin-FITC fluorescence. Top row, Human aortic myofibroblast (phalloidin stain, orange) and nuclear (Hoechst stain, blue) staining. Middle row, Cell gelatin-FITC fluorescence (green) relative to background fluorescence. Bottom row, Merged images. B, Quantification of cell gelatin-FITC fluorescence relative to untreated cells. Horizontal lines denote median values and $P$ value indicates comparison to $0 \mu \mathrm{M}$ fluoroquinolone (Friedman's test with Dunn's test for multiple comparisons). There were 4 replicates. White line indicates scale. $F Q$, Fluoroquinolone.

\section{FQ Exposure Supresses Human Aortic Myofibroblast Collagen-1 Expression}

Biomechanical stability requires collagen deposition to compensate for ongoing collagen fiber degradation. To delineate the functional effects of the FQ-mediated protease profile on ECM integrity, collagen-1 protein expression was assessed in human aortic myofibroblasts using immunoblotting and immunofluorescent staining. Collagen-1 protein was significantly decreased at $500 \mu \mathrm{m}$ FQ compared with vehicle control by both immunoblotting ( 0.19 optical density [IQR, $0.01-0.23$ optical density] vs 1.35 optical density [IQR, 0.86-1.56 optical density]; $P=.002$ ) (Figure 4, A and $B$ ), as well as using immunofluorescent staining ( 0.26 mean fluorescence [IQR, 0.19-0.36 mean fluorescence] vs 0.77 mean fluorescence [IQR, 0.69-0.93 mean fluorescence]; $P=.02$ ) (Figure 4, $C$ and $D$ ). Cell morphology was not altered by FQ exposure (Figure $4, C$ ). In a small sample $(n=2)$ of nonaortic human atrial cardiac myofibroblasts, we observed a similar trend of decreased collagen-1 fluorescence with FQ exposure (Figure E2).

\section{Aortic Myofibroblast Cell Death and Viability Are Not Altered by FQ Exposure}

We next assessed whether the observed effects of FQ on ECM regulation were the result of a nonspecific influence on cell health or metabolism. Indices of cell viability were determined by annexin- $\mathrm{V}$ and propidium iodide staining for apoptosis and necrosis, respectively, and metabolism was compared using the WST1 assay. Low levels ( $<5 \%$ total cells) of late apoptosis/necrosis $(P=.71)$ (Figure 5, $A$ and $B)$ or early apoptosis $(P=.93$ ) (Figure $5, A$ and $C$ ) were observed in human aortic myofibroblasts following either vehicle or FQ exposure. Similarly, FQ exposure did not significantly influence cell metabolism based on the WST1 assay $(P=.35)$ (Figure $5, D)$.

\section{DISCUSSION}

Aortopathy is characterized by remodeling and degradation of aortic wall ECM components. ECM dysregulation results in progressive weakening and aneurysmal outward vessel enlargement that substantially increases a patient's risk of acute dissection or rupture. ${ }^{2}$ Exposure to key environmental triggers can exacerbate aortic ECM remodeling. For example, elevated wall shear stress as documented in patients with bicuspid aortic valve is associated with exacerbated ECM disruption. ${ }^{28}$ Emerging evidence implicates exposure to $\mathrm{FQ}$ as a putative environmental trigger and potentially modifiable acquired mechanism of disease. ${ }^{3-6}$ People exposed to routine use of FQ face a significantly increased risk of aortic aneurysm (odds ratio, 2.25; 95\% confidence interval, 2.03-2.49) and acute aortic dissection (odds ratio, 2.79; 95\% confidence interval, 2.31-3.37) as highlighted by a recent meta-analysis of numerous clinical reports. ${ }^{5}$ With more than 27 million annual prescriptions in the United States, ${ }^{7}$ use of FQ remains commonplace despite its known association with ECM disease manifesting as acute tendon ruptures. ${ }^{29}$ 

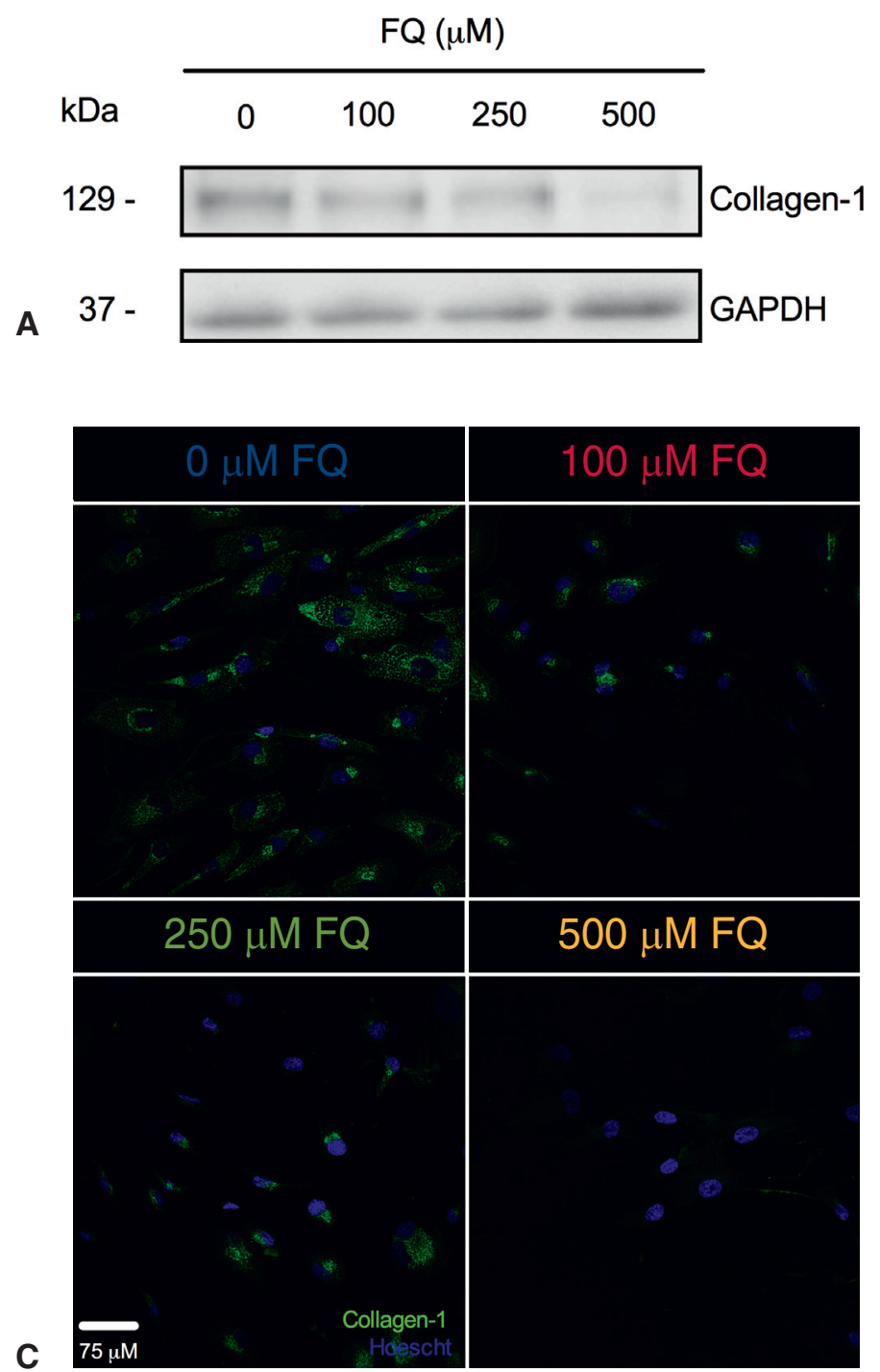
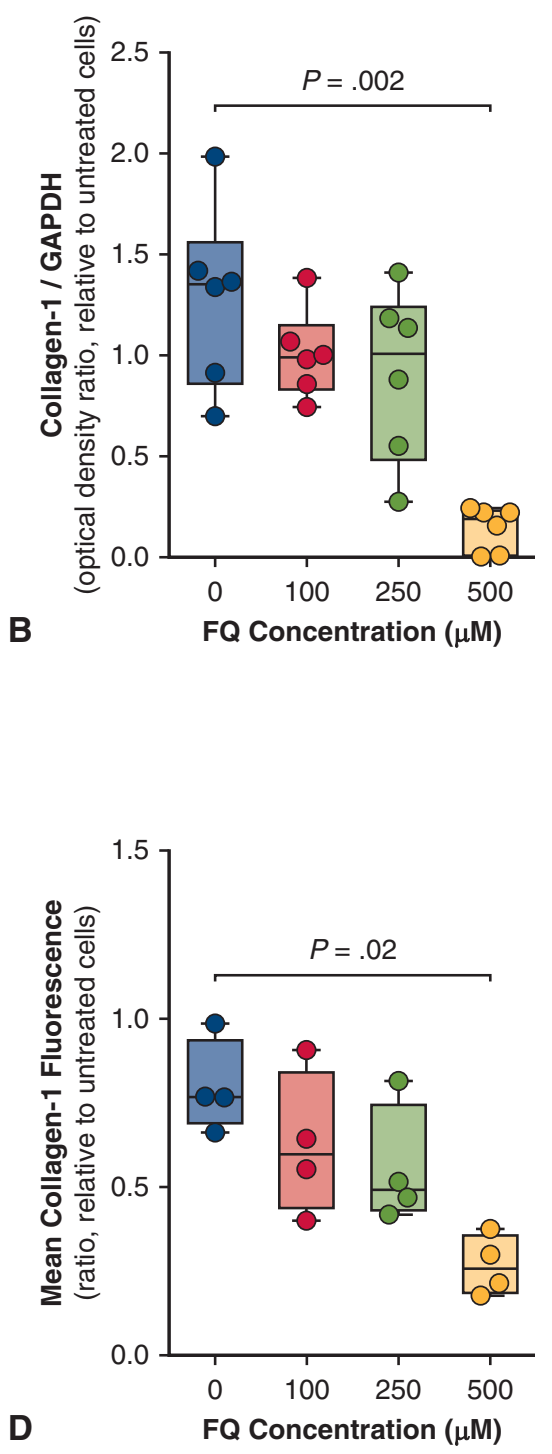

FIGURE 4. Collagen-1 expression in human aortic myofibroblasts exposed to fluoroquinolone $(F Q)$. A and B, Representative collagen-1 Western blot and quantified optical density relative to glyceraldehyde 3-phosphate dehydrogenase (GAPDH) loading control; (6 replicates). C and D, Immunofluorescent staining of collagen-1 (green) and nuclei (Hoechst stain, blue). Horizontal lines denote median values and $P$ values indicate comparison to $0 \mu \mathrm{M}$ FQ (Friedman's test with Dunn's test for multiple comparisons). There were 4 replicates. White line indicates scale.

An underlying mechanism that explains FQ-associated aortopathy is unclear. ${ }^{5}$ Myofibroblasts coordinate ECM remodeling in health and disease by secreting ECM proteases (ie, MMPs) and endogenous inhibitors (ie, TIMPs) in balance with compensatory collagen deposition. ${ }^{13,30}$ ECM homeostasis is maintained by a tight regulation of these competing processes. Dysregulation of ECM homeostasis can disrupt aortic ECM integrity and impair biomechanical strength leading to progressive aortic weakening, dissection, or rupture. ${ }^{31}$ We hypothesized that an imbalance of ECM regulatory processes induced by FQ exposure may trigger cell-mediated maladaptive aortic ECM remodeling that weakens tissue and predisposes patients to aneurysm, dissection, or rupture. ${ }^{13-19}$ In this study, we show for the first time that FQ exposure induces a proteolytic MMP-TIMP imbalance driven by decreased TIMP expression in human aortic myofibroblasts from patients with known aortopathy. We document that FQ exposure to human aortic cells can induce ECM dysregulation resulting in disruption of collagen fibers while simultaneously attenuating collagen ECM expression in the face of enhanced degradation (Figure 6). We confirm that the observed effects were not due to nonspecific cell injury from exposure to FQ. Furthermore, we observed similar trends in a small sample of nonaortic human atrial cardiac myofibroblasts. These data illustrate that although FQ exposure has deleterious effects on human cardiovascular myofibroblasts irrespective of the site of origin, these effects 

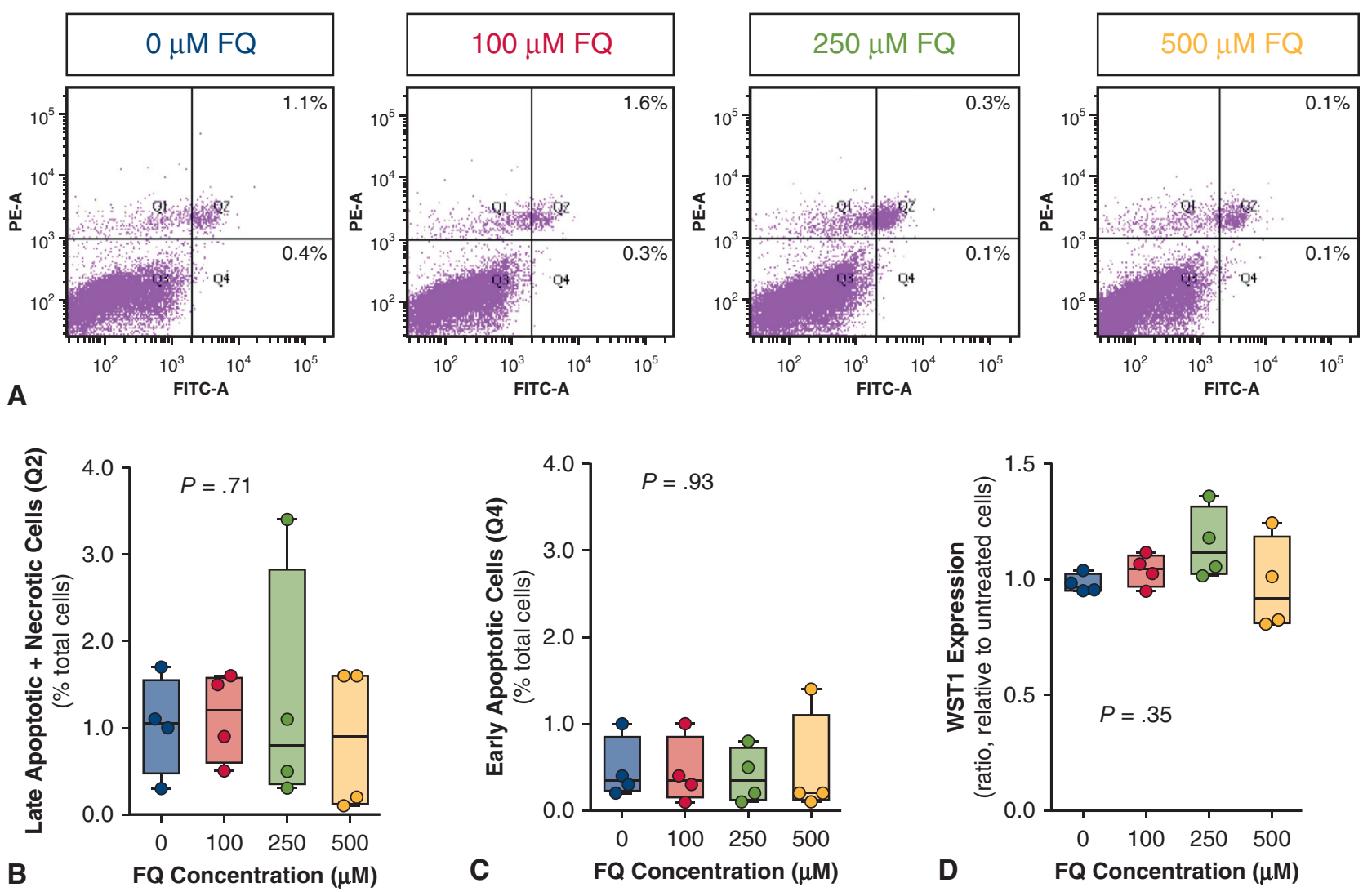

FIGURE 5. Apoptosis, necrosis, and cell metabolic activity of human aortic myofibroblasts exposed to fluoroquinolone $(F Q)$. A, Representative flow cytometry of cells double-stained with annexin-V (fluorescein isothiocyanate $[F I T C]$ ) and propidium iodide (phycoerythrin $[P E]$ ). Percentages of late apoptotic/necrotic and early apoptotic cells are shown in the top right quadrants (Q2 and Q4, respectively). B, Percent of late apoptotic/necrotic cells are shown. C, Percent of early apoptotic cells are shown. D, Comparison of cell metabolic activity for different FQ exposures using water-soluble tetrazolium salt assay relative to untreated cells. Horizontal lines denote median values and $P$ values denote comparison between 100,250 , and 500 $\mu \mathrm{M} \mathrm{FQ}$ and $0 \mu \mathrm{M} \mathrm{FQ}$ (Friedman's test with Dunn's test for multiple comparisons). There were 4 replicates.

may result in progressive aortic wall weakening leading to the adverse aortic events associated with patients receiving FQ antibiotics.

Increased collagen deposition can be an adaptive and protective response to hemodynamic stress despite eventual maladaptive consequences of tissue fibrosis. ${ }^{31}$ Bujor and colleagues $^{32}$ similarly observed FQ-mediated antifibrotic activity in sclerodermal fibroblasts, consistent with others who report decreased collagen-1 gene transcript and protein expression in tendon cells following FQ exposure. ${ }^{10,11}$ These findings may be attributable to impaired collagen fiber maturation because Badal and colleagues ${ }^{21}$ documented reduced collagen proline hydroxylation and inhibition of collagen prolyl 4-hydroxylase in human embryonic kidney cells. Our study confirms and extends these findings to aortic myofibroblasts from human aortopathy patients. For patients with underlying aortopathy such as those included in this study, a reduced aortic myofibroblast capacity for collagen-1 synthesis in response to FQ may confer biomechanical fragility to the aortic wall. As such, our study describes a possible mechanism that may explain how FQ exposure increases risk of acute aortic dissection or rupture. Similarly, Fox and colleagues ${ }^{12}$ report that prolonged FQ use impaired healing and decreased the threshold for tendon failure in a rat model of rotator cuff injury.

Previous studies in tendon and cartilage cells suggest maladaptive FQ-mediated ECM remodeling may be attributable to increased protease activity resulting from elevated MMPs. ${ }^{9,10}$ Although we also document an imbalance in the MMP-TIMP axis, our data support a mechanism whereby increased protease activity is largely driven by a reduction in TIMP inhibition. FQ induces a profound decrease in aortic cell TIMP-1 and TIMP-2 expression protein expression, both of which are key mediators of aneurysm pathogenesis. ${ }^{26}$ For example, TIMP reductions can worsen aortopathy in murine models of human aortic disease, ${ }^{33,34}$ and decreased TIMP levels are documented in human aneurysmal aortic tissue. ${ }^{26}$ We report decreased levels of several MMPs in response to FQ exposure, whereas MMP-9, a critical gelatinase mediator of aortopathy pathogenesis, ${ }^{24,26}$ was unchanged by FQ exposure. 


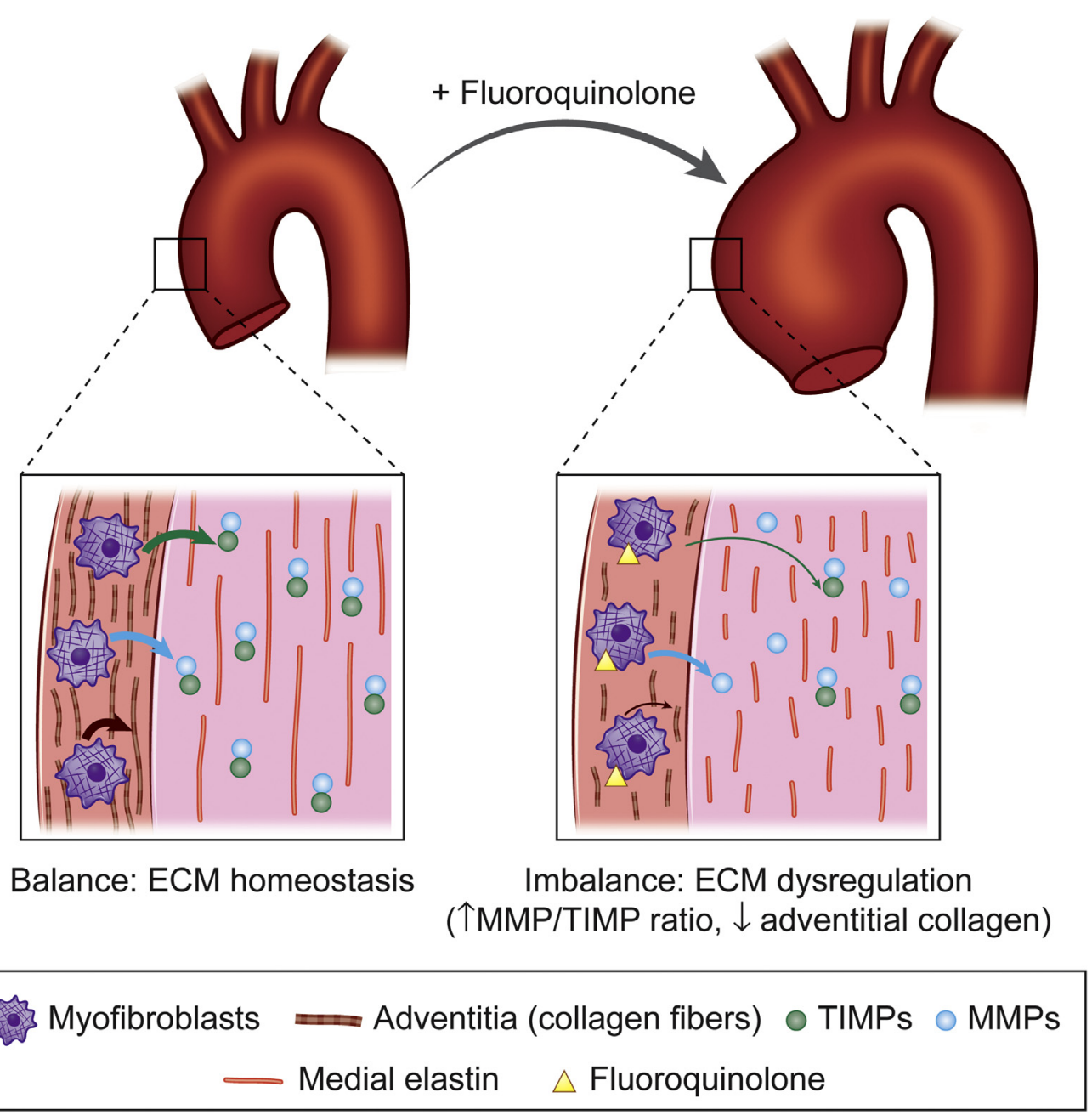

FIGURE 6. Fluoroquinolone-induced human aortic myofibroblast-mediated extracellular matrix (ECM) dysregulation. Fluoroquinolone antibiotics generate an imbalance in metalloproteinases (MMPs) and tissue inhibitor of MMPs (TIMPs) resulting in ECM degradation alongside impaired myofibroblast-mediated collagen expression. These findings support a putative mechanism underlying fluoroquinolone drug exposure and the increased incidence of aortic aneurysm.

We report that although an in vitro FQ concentration of $100 \mu \mathrm{m}$ does not alter the MMP-TIMP axis and local ECM integrity of human aortic myofibroblasts compared with vehicle control, a trend begins to emerge upon exposure to $250 \mu \mathrm{m}$ FQ. By $500 \mu \mathrm{m}$ FQ, significant decreases in TIMP abundance, increases in ECM degradation, and impairment of collagen- 1 expression are noted. These data suggest an inflection point where a safe therapeutic window may exist. Mild FQ doses for short periods are likely well tolerated by most patients, but higher doses and for longer periods, especially in those patients with pre-existing aortopathy, may increase the susceptibility to FQ-associated acute aortic events. Patients with genetic connective tissue disorders and those with bicuspid aortic valve-associated aortopathy with preexisting abnormalities of aortic wall structure and function may be most susceptible. ${ }^{35}$
We acknowledge numerous limitations of this study. Our findings are limited to human aortic myofibroblasts. The effects of FQ on vascular smooth muscle cells may be equally important and future studies should investigate their direct contribution to FQ-associated aortopathy. Furthermore, animal models that can recapitulate the clinical phenotype will be important to delineate the biomechanical and hemodynamic thresholds that are altered by FQ exposure timing and dosing. We also recognize that the influence of FQ exposure on cells obtained from patients with variable comorbidities and clinical phenotypes such as aortic valve morphology (bicuspid vs tricuspid valve) and connective tissue defects such as Marfan syndrome may differ. Future adequately powered studies are warranted to clarify differences between these subsets of patients. 


\section{CONCLUSIONS}

FQ induces human aortic myofibroblast-mediated ECM dysregulation by decreasing TIMP expression and preventing compensatory collagen deposition. These data provide novel insights into the mechanisms that may underlie the clinical association of FQ exposure and increased risk of acute aortic events in the community. Our data suggest cautious use of FQ in selected patient populations with pre-existent aortopathy and connective tissue disorders.

\section{Webcast}

You can watch a Webcast of this AATS meeting presentation by going to: https://aats.blob.core.windows.net/media/ 18AO/27-GramEast-0620-guzzardi-v2.mp4.

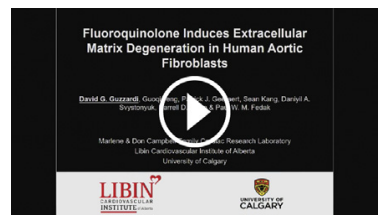

\section{Conflict of Interest Statement}

Authors have nothing to disclose with regard to commercial support.

\section{References}

1. Elefteriades JA, Farkas EA. Thoracic aortic aneurysm. J Am Coll Cardiol. 2010; 55:841-57.

2. Wu D, Shen YH, Russell L, Coselli JS, LeMaire SA. Molecular mechanisms of thoracic aortic dissection. J Surg Res. 2013;184:907-24.

3. Daneman N, Lu H, Redelmeier DA. Fluoroquinolones and collagen associated severe adverse events: a longitudinal cohort study. BMJ Open. 2015;5:e010077.

4. Lee C-C, Lee M-TG, Chen Y-S, Lee S-H, Chen Y-S, Chen S-C, et al. Risk of aortic dissection and aortic aneurysm in patients taking oral fluoroquinolone. JAMA Intern Med. 2015;175:1839-47.

5. Singh S, Nautiyal A. Aortic dissection and aortic aneurysms associated with fluoroquinolones: a systematic review and meta-analysis. Am J Med. 2017;130: 1449-57.e9.

6. Pasternak B, Inghammar M, Svanström H. Fluoroquinolone use and risk of aortic aneurysm and dissection: nationwide cohort study. BMJ. 2018;k678.

7. Hicks LA, Bartoces MG, Roberts RM, Suda KJ, Hunkler RJ, Taylor TH, et al. US outpatient antibiotic prescribing variation according to geography, patient population, and provider specialty in 2011. Clin Infect Dis. 2015;60:1308-16.

8. Williams RJ, Attia E, Wickiewicz TL, Hannafin JA. The effect of ciprofloxacin on tendon, paratenon, and capsular fibroblast metabolism. Am J Sports Med. 2000;28:364-9.

9. Corps AN, Harrall RL, Curry VA, Fenwick SA, Hazleman BL, Riley GP. Ciprofloxacin enhances the stimulation of matrix metalloproteinase 3 expression by interleukin-1 $\beta$ in human tendon-derived cells: a potential mechanism of fluoroquinolone-induced tendinopathy. Arthritis Rheum. 2002;46:3034-40.

10. Tsai WC, Hsu CC, Chen CPC, Chang HN, Wong AMK, Lin MS, et al. Ciprofloxacin up-regulates tendon cells to express matrix metalloproteinase-2 with degradation of type I collagen. J Orthop Res. 2011;29:67-73.

11. Chang HN, Pang JHS, Chen CPC, Ko PC, Lin MS, Tsai WC, et al. The effect of aging on migration, proliferation, and collagen expression of tenocytes in response to ciprofloxacin. J Orthop Res. 2012;30:764-8.

12. Fox A, Schar M, Wanivenhaus F, Chen T, Attia E, Binder N, et al. Fluoroquinolones impair tendon healing in a rat rotator cuff repair model: a preliminary study. Am J Sports Med. 2014;42:2851-9.

13. Forte A, Della Corte A, De Feo M, Cerasuolo F, Cipollaro M. Role of myofibroblasts in vascular remodelling: focus on restenosis and aneurysm. Cardiovasc Res. 2010;88:395-405.
14. Maegdefessel L, Azuma J, Toh R, Merk DR, Deng A, Chin JT, et al. Inhibition of microRNA-29b reduces murine abdominal aortic aneurysm development. J Clin Invest. 2012;122:497-506.

15. Tieu BC, Lee C, Sun H, LeJeune W, Recinos A, Ju X, et al. An adventitial IL-6 MCP1 amplification loop accelerates macrophage-mediated vascular inflammation leading to aortic dissection in mice. J Clin Invest. 2009;119:3637-51.

16. Tieu BC, Ju X, Lee C, Sun H, Lejeune W, Recinos A, et al. Aortic adventitial fibroblasts participate in angiotensin-induced vascular wall inflammation and remodeling. J Vasc Res. 2011;48:261-72.

17. Forte A, Della Corte A, Grossi M, Bancone C, Maiello C, Galderisi U, et al. Differential expression of proteins related to smooth muscle cells and myofibroblasts in human thoracic aortic aneurysm. Histol Histopathol. 2013;28:795-803.

18. Jones JA, Beck C, Barbour JR, Zavadzkas JA, Mukherjee R, Spinale FG, et al Alterations in aortic cellular constituents during thoracic aortic aneurysm development myofibroblast-mediated vascular remodeling. Am J Pathol. 2009;175: $1746-56$.

19. Jones JA, Zavadzkas JA, Chang EI, Sheats N, Koval C, Stroud RE, et al. Cellular phenotype transformation occurs during thoracic aortic aneurysm development. $J$ Thorac Cardiovasc Surg. 2010;140:653-9.

20. Teng G, Svystonyuk D, Mewhort HEM, Turnbull JD, Belke DD, Duff HJ, et al Tetrandrine reverses human cardiac myofibroblast activation and myocardial fibrosis. Am J Physiol Circ Physiol. 2015;308:H1564-74.

21. Badal S, Her YF, Maher LJ. Nonantibiotic effects of fluoroquinolones in mammalian cells. J Biol Chem. 2015;290:22287-97.

22. Wagenlehner FME, Wydra S, Onda H, Kinzig-Schippers M, Sörgel F, Naber KG Concentrations in plasma, urinary excretion, and bactericidal activity of linezolid (600 milligrams) versus those of ciprofloxacin (500 milligrams) in healthy volunteers receiving a single oral dose. Antimicrob Agents Chemother. 2003;47: 3789-94.

23. McCloy RA, Rogers S, Caldon CE, Lorca T, Castro A, Burgess A. Partial inhibition of Cdk1 in G 2 phase overrides the SAC and decouples mitotic events. Cell Cycle. 2014;13:1400-12.

24. Jones JA, Barbour JR, Lowry AS, Bouges S, Beck C, McClister DM, et al. Spatiotemporal expression and localization of matrix metalloproteinase-9 in a murine model of thoracic aortic aneurysm. J Vasc Surg. 2006;44:1314-21.

25. Ikonomidis JS, Barbour JR, Amani Z, Stroud RE, Herron AR, McClister DM, et al. Effects of deletion of the matrix metalloproteinase 9 gene on development of murine thoracic aortic aneurysms. Circulation. 2005;112(9 Suppl):I242-8.

26. Rabkin SW. Differential expression of MMP-2, MMP-9 and TIMP proteins in thoracic aortic aneurysm - comparison with and without bicuspid aortic valve: a meta-analysis. Vasa. 2014;43:433-42.

27. Giannandrea M, Parks WC. Diverse functions of matrix metalloproteinases during fibrosis. Dis Model Mech. 2014;7:193-203.

28. Guzzardi DG, Barker AJ, Van Ooij P, Malaisrie SC, Puthumana JJ, Belke DD, et al. Valve-related hemodynamics mediate human bicuspid aortopathy: insights from wall shear stress mapping. J Am Coll Cardiol. 2015;66:892-900.

29. Stephenson AL, Wu W, Cortes D, Rochon PA. Tendon injury and fluoroquinolone use: a systematic review. Drug Saf. 2013;36:709-21.

30. Klingberg F, Hinz B, White ES. The myofibroblast matrix: implications for tissue repair and fibrosis. J Pathol. 2013;229:298-309.

31. Hoefer IE, den Adel B, Daemen MJAP. Biomechanical factors as triggers of vascular growth. Cardiovasc Res. 2013;99:276-83.

32. Bujor AM, Haines P, Padilla C, Christmann RB, Junie M, SampaioBarros PD, et al. Ciprofloxacin has antifibrotic effects in scleroderma fibroblasts via downregulation of Dnmt1 and upregulation of Fli1. Int J Mol Med. 2012;30:1473-80.

33. Silence J, Collen D, Lijnen HR. Reduced atherosclerotic plaque but enhanced aneurysm formation in mice with inactivation of the tissue inhibitor of metalloproteinase-1 (TIMP-1) gene. Circ Res. 2002;90:897-903.

34. Eskandari MK, Vijungco JD, Flores A, Borensztajn J, Shively V, Pearce WH Enhanced abdominal aortic aneurysm in TIMP-1-deficient mice. J Surg Res 2005; 123:289-93.

35. Fedak PWM, De Sa MPL, Verma S, Nili N, Kazemian P, Butany J, et al Vascular matrix remodeling in patients with bicuspid aortic valve malformations: implications for aortic dilatation. J Thorac Cardiovasc Surg. 2003;126: 797-806.

Key Words: fluoroquinolone, aortopathy, extracellular matrix 


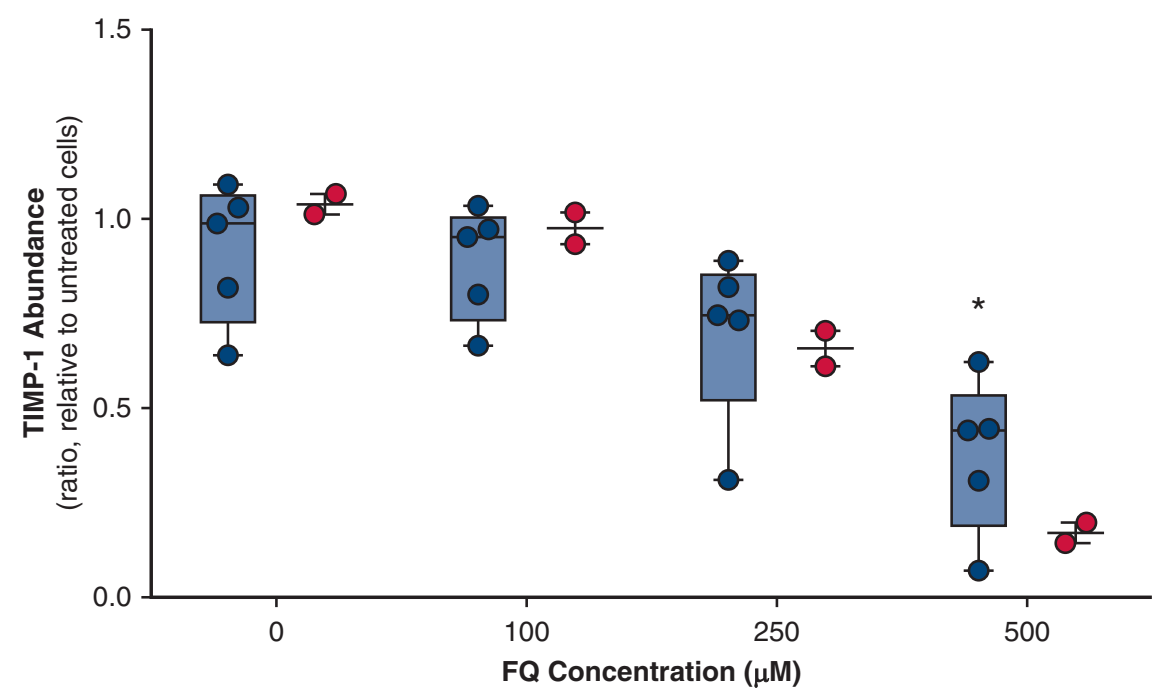

A

$\square$ Adventitial Myofibroblasts $\square$ Atrial Myofibroblasts

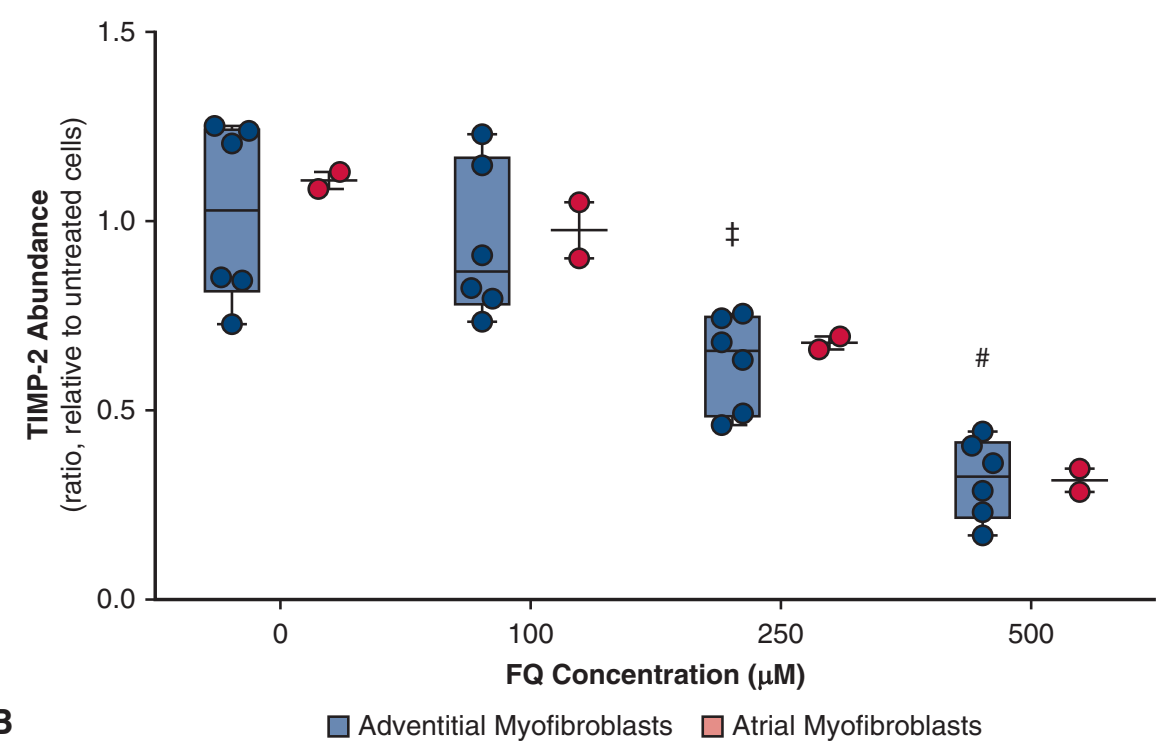

FIGURE E1. Comparison of tissue inhibitor of matrix metalloproteinase (TIMP) protein released by human aortic (blue) and atrial (red) myofibroblasts exposed to fluoroquinolone $(F Q)$, relative to untreated cells. A and B, TIMP-1 and -2. Horizontal lines denote median values. Within-aortic group comparisons to $0 \mu \mathrm{M} \mathrm{FQ}$ (Friedman's test with Dunn's test for multiple comparisons): $* P=.004$. $\ddagger P=.04$. $\# P=.0004$. There were 5 and 6 replicates for aortic myofibroblasts in Panel A and Panel B, respectively. There were 2 replicates for atrial myofibroblasts. 

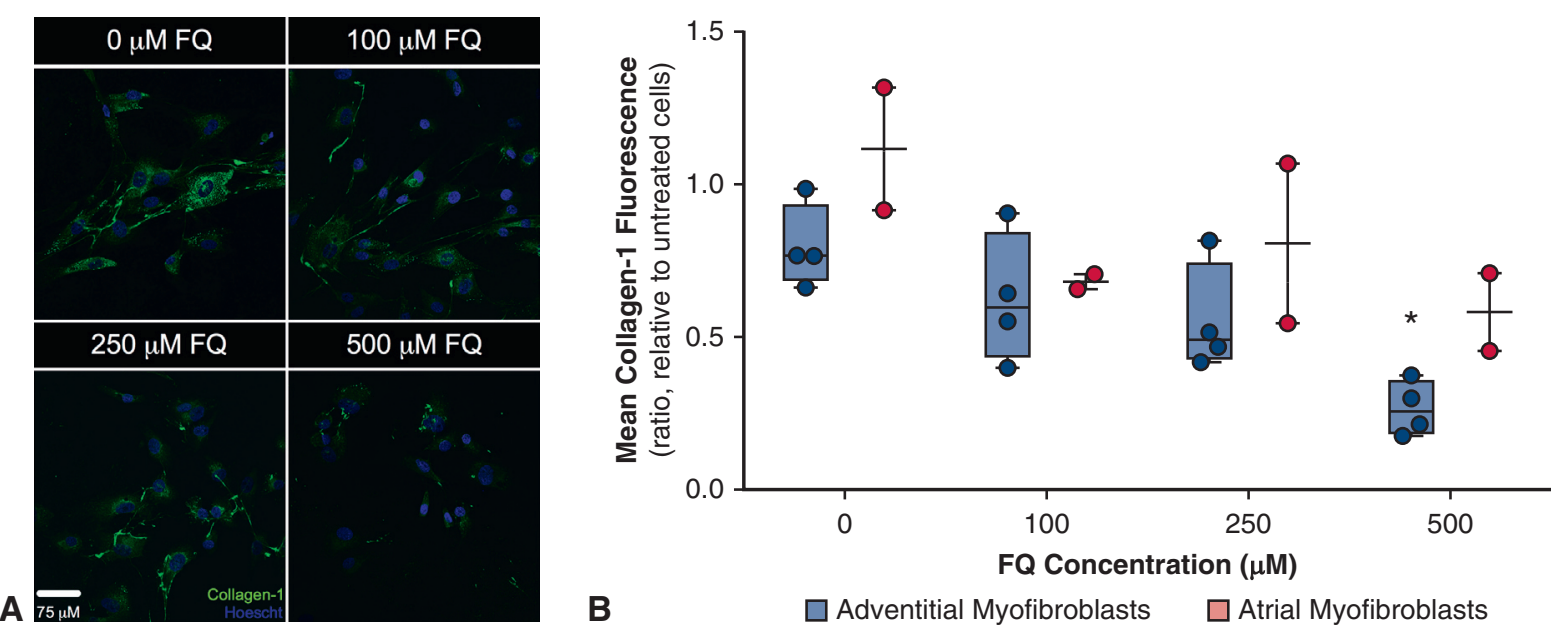

FIGURE E2. Comparison of immunofluorescent staining of collagen-1 (green) and nuclei (Hoechst stain, blue) in human aortic (blue) and atrial (red) myofibroblasts exposed to fluoroquinolone $(F Q)$. A, Representative images of human atrial cardiac myofibroblasts. B, Quantification of immunofluorescent collagen-1 staining. Horizontal lines denote median values. Within-aortic group comparison to $0 \mu \mathrm{M}$ FQ (Friedman's test with Dunn's test for multiple comparisons): $* P=.02$. There were 4 and 2 replicates for aortic and atrial myofibroblasts, respectively. White line indicates scale. 